\title{
Synthesis, spectroscopy and supramolecular structures of two magnesium 4-nitrobenzoate complexes ${ }^{\#}$
}

\author{
BIKSHANDARKOIL R SRINIVASAN,${ }^{1, *}$ JYOTI V SAWANT,${ }^{1}$ CHRISTIAN NÄTHER ${ }^{2}$ and \\ WOLFGANG BENSCH ${ }^{2}$ \\ ${ }^{1}$ Department of Chemistry, Goa University, Goa 403206 \\ ${ }^{2}$ Institut für Anorganische Chemie, Christian-Albrechts-Universität Kiel, Olshausenstraße 40, D-24098 \\ Kiel, Germany \\ e-mail: srini@unigoa.ac.in
}

MS received 1 February 2007; revised 16 May 2007

\begin{abstract}
The aqueous reaction of $\left[\mathrm{Mg}\left(\mathrm{H}_{2} \mathrm{O}\right)_{6}\right] \mathrm{Cl}_{2}$ with the in situ generated sodium salt of 4-nitrobenzoic acid (4-nbaH) and $\mathrm{N}$-methylimidazole $(\mathrm{N}-\mathrm{MeIm})$ results in the formation of the dinuclear complex $\left[\mathrm{Mg}\left(\mathrm{H}_{2} \mathrm{O}\right)(\mathrm{N}-\mathrm{MeIm})_{2}(4-\mathrm{nba})_{2}\right]_{2} \mathbf{1}$ (4-nba = 4-nitro benzoate), while the direct reaction of $\left[\mathrm{Mg}\left(\mathrm{H}_{2} \mathrm{O}\right)_{6}\right] \mathrm{Cl}_{2}$ with sodium 4-nba leads to the formation of the mononuclear complex, $\left[\mathrm{Mg}\left(\mathrm{H}_{2} \mathrm{O}\right)_{6}\right](4-n b a)_{2} \cdot 2 \mathrm{H}_{2} \mathrm{O} 2$. In the centrosymmetric dimer 1 , each $\mathrm{Mg}$ atom is coordinated to an aquo ligand, two monodentate $\mathrm{N}-\mathrm{MeIm}$ ligands and a monodentate 4-nba ligand. The second 4-nba ligand functions as a bridging bidentate ligand, linking the metal centers and completes the hexacoordination around each $\mathrm{Mg}(\mathrm{II})$. The dimeric molecules of 1 are linked into a one-dimensional chain along $b$ with the aid of intra- as well as intermolecular H-bonding interactions between the coordinated water and the free oxygen atom of the monodentate 4-nba ligand. In the mononuclear complex $\left[\mathrm{Mg}\left(\mathrm{H}_{2} \mathrm{O}\right)_{6}\right](4-\mathrm{nba})_{2} \cdot 2 \mathrm{H}_{2} \mathrm{O} 2$, the $\mathrm{Mg}(\mathrm{II})$ is located on an inversion center and its structure consists of an octahedral $\left[\mathrm{Mg}\left(\mathrm{H}_{2} \mathrm{O}\right)_{6}\right]^{2+}$ dication, a free uncoordinated 4nba anion and a lattice water molecule. One of the $\mathrm{H}$ atoms attached of the lattice water is disordered over two positions. The hexaaquomagnesium(II) dication, the 4-nba anion and the lattice water molecule are linked by intra- and intermolecular $\mathrm{H}$-bonding interactions resulting in the formation of alternating layers of $\left[\mathrm{Mg}\left(\mathrm{H}_{2} \mathrm{O}\right)_{6}\right]^{2+}$ dications and 4-nba anions in the crystallographic $b c$ plane. The lattice water molecules are situated between the cations, while the 4-nba anions are arranged antiparallel to each other along $b$.
\end{abstract}

Keywords. 4-Nitrobenzoic acid; N-methylimidazole; monodentate; bridging bidentate; H-bonding interactions; hexaaquomagnesium(II).

\section{Introduction}

Magnesium is a biologically relevant element in view of its widespread occurrence in nature (e.g. $\mathrm{Mg}$ in chlorophyll) and in the body. $\mathrm{Mg}(\mathrm{II})$ plays an essential role in the activation of enzymes, complexation with nucleic acids, nerve impulse transmission etc. Hence the study of $\mathrm{Mg}(\mathrm{II})$ complexes has been undertaken by several research groups in order to understand the mode of binding of $\mathrm{Mg}$ (II) in vivo and in vitro. ${ }^{1-3}$ Many of these studies have focused on the use of carboxylate ligands like aspartate, glutamate, salicylic acid and more recently amino and

\footnotetext{
${ }^{\#}$ Dedicated to Prof. Dr. Werner Weisweiler on the occasion of his 69th birthday

*For correspondence
}

mercaptobenzoates. ${ }^{4-14}$ While such studies are important to enhance our understanding of $\mathrm{Mg}$ biochemistry, a recent interest in this area is in terms of the rich structural chemistry exhibited by the alkaliearth metal complexes. It is to be noted that the carboxylate group is a versatile ligand and exhibits a variety of binding modes. ${ }^{15,16}$ This property of the carboxylate ligand combined with the fact that many metal-carboxylates are hydrated and contain both coordinated as well as crystal water molecules, which can participate in $\mathrm{H}$-bonding interactions, ${ }^{17,18}$ can be used to construct novel supramolecular metal-organic architectures. The study of crystalline hydrates is an area of current research, ${ }^{19}$ as these compounds can function as molecular containers for trapping small water clusters, which exhibit interesting structures of $\mathrm{H}$-bonded water molecules. ${ }^{20,21}$ 
In the earlier work we have investigated the spectral and thermal characteristics of hydrated $\mathrm{Mg}$ (II)complexes of the isomeric nitrobenzoic acids and had attributed their dehydration characteristics at higher temperatures to the differing nature of $\mathrm{H}$ bonding interactions of the nitro group as compared to the amino analogue. ${ }^{22}$ As part of this research ${ }^{23,24}$ we are investigating the synthesis and structural aspects of alkali-earth nitrobenzoates with $\mathrm{N}$-donor ligands and have recently reported the structures of the mixed ligand complexes $\left[\mathrm{Mg}\left(\mathrm{H}_{2} \mathrm{O}\right)_{2}(\mathrm{Im})_{2}(4-\mathrm{nba})_{2}\right]$ and $\left[\mathrm{Ca}\left(\mathrm{H}_{2} \mathrm{O}\right)_{3}(\mathrm{Im})(4-\mathrm{nba})_{2}\right] \cdot \mathrm{Im} \quad(\mathrm{Im}=$ imidazole $){ }^{25}$ In continuation of this work, we wish to describe the synthesis, spectral and structural characterization of the dimeric $\mathrm{Mg}(\mathrm{II})$ complex obtained by using $\mathrm{N}$ methylimidazole (N-MeIm) as the $\mathrm{N}$-donor ligand. In addition, the crystal structure of $\left[\mathrm{Mg}\left(\mathrm{H}_{2} \mathrm{O}\right)_{6}\right](4-$ $\mathrm{nba})_{2} \cdot 2 \mathrm{H}_{2} \mathrm{O}$ is described in this paper.

\section{Experimental}

\subsection{Materials and methods}

All the chemicals used in this study were of reagent grade and were used as received. The starting materials as well as reaction products are quite stable in air and hence were routinely prepared under normal laboratory conditions. The details of instrumentation were the same as described in our earlier reports. ${ }^{24,25}$ The insoluble 4-nitrobenzoic acid (4-nbaH) obtained on acid treatment of the complexes was weighed as described earlier ${ }^{22}$ and metal analysis was performed titrimetrically following a standard procedure. ${ }^{26}$

\subsection{Preparation of $\left[\mathrm{Mg}\left(\mathrm{H}_{2} \mathrm{O}\right)(\mathrm{N}-\mathrm{MeIm})_{2}(4-n b a)_{2}\right]_{2}$ 1 and $\left[\mathrm{Mg}\left(\mathrm{H}_{2} \mathrm{O}\right)_{6}\right](4-n b a)_{2} \cdot 2 \mathrm{H}_{2} \mathrm{O} 2$}

A mixture of $\mathrm{MgCO}_{3}(0.84 \mathrm{~g}, 10 \mathrm{mmol})$ and 4-nbaH $(3.34 \mathrm{~g}, 20 \mathrm{mmol})$ was taken in water $(50 \mathrm{ml})$ and heated on a steam bath. The insoluble starting materials slowly started dissolving as evidenced by the brisk effervescence. The heating of the reaction mixture was stopped when there was no more evolution of $\mathrm{CO}_{2}$. At this stage the reaction mixture was almost clear and the $\mathrm{pH}$ was close to neutral. The reaction mixture was filtered and N-MeIm $(3.2 \mathrm{ml}, 40 \mathrm{mmol})$ was added to the hot filtrate. The solution was stirred and concentrated to around $10 \mathrm{ml}$ and left undisturbed for a few days. The pale yellow crystalline blocks that separated were filtered, washed thoroughly with ether and dried in air. Yield 89\%. Complex 1 can also be prepared by using magnesium chloride as the $\mathrm{Mg}$ source. $\left[\mathrm{Mg}\left(\mathrm{H}_{2} \mathrm{O}\right)_{6}\right] \mathrm{Cl}_{2}(2.03 \mathrm{~g}, 10 \mathrm{mmol})$ was dissolved in water $(10 \mathrm{ml})$. Into this, an aqueous solution $(40 \mathrm{ml})$ of sodium salt of 4-nbaH generated in situ from 4-nbaH $(3.34 \mathrm{~g}, 20 \mathrm{mmol}), \mathrm{NaHCO}_{3}$ $(1.68 \mathrm{~g}, 20 \mathrm{mmol})$ was added, followed by the addition of N-MeIm $(3.2 \mathrm{ml}, 40 \mathrm{mmol})$. The reaction mixture was concentrated to about $15 \mathrm{ml}$, filtered and kept aside for crystallization. The pale yellow crystalline blocks of 1 that separated after a week were filtered, washed with ice-cold water $(2 \mathrm{ml})$, followed by ether and dried in air. Yield: $77 \%$. The IR spectra of the complexes obtained in both the methods are identical. In the absence of any added $\mathrm{N}-\mathrm{MeIm}$ into the reaction mixture, the mononuclear complex 2 was isolated in $90 \%$ yield.

IR data 1 in $\mathrm{cm}^{-1} 3441(s), 3129(s), 3105(s)$, $3053(s), 2884(w), 2818(w), 2610(w), 2444(w)$, $2272(w), 2207(w), 1944(w), 1807(w), 1720(m)$, $1645(s), 1614(s), 1582(s), 1516(s), 1487(m)$, $1404(s), 1346(s), 1319(s), 1287(s), 1238(s), 1173$ $(w), 1142(w), 1107(s), 1088(s), 1028(m), 1015$ $(m), 968(w), 939(s), 880(s), 868(s), 827(s), 802$ $(s), 781(s), 758(s), 725(s), 702(s), 667(s), 621$ $(s), 563(s), 517(s)$.

Analysis - Found (calcd.) for $\mathrm{C}_{44} \mathrm{H}_{44} \mathrm{Mg}_{2} \mathrm{~N}_{12} \mathrm{O}_{18} \mathbf{1}$ : Mg 4.54 (4.51); 4-nbaH 60.25 (61.65); C 49.09 (49.01); H 4.20 (4.12); N 15.84 (15.59); $\mathrm{MgO} 7.83$ (7.48).

\subsection{X-ray crystal structure determination}

Intensity data for 1 was collected on a STOE Image Plate Diffraction System and on an AED-II four circle diffractometer for 2, using graphite-monochromated Mo-K $\mathrm{K}_{\alpha}$ radiation $(\lambda=0.71069 \AA)$. The structures were solved with direct methods using SHELXS$97^{27}$ and refinement was done against $F^{2}$ using SHELXL-97. ${ }^{27}$ All non-hydrogen atoms were refined anisotropically. Aromatic hydrogens were introduced at their calculated positions and included in the refinement riding on their respective parent atoms. In compound 1 the $\mathrm{H}$-atoms attached to the C34 of the methyl group of the N-MeIm ligand are disordered in two orientations rotated by $60^{\circ}$ relative to each other. Therefore, they were refined using the HFIX 127 command for disordered methyl groups in SHELXL-97. In compound 2 one of the $\mathrm{H}$ atoms (H80) attached to the lattice water $(\mathrm{Ol})$ is disordered over two positions and was refined using a split model with site occupation factors of $50: 50$. 
Table 1. Technical details of data acquisition and selected refinement results for $\mathbf{1}$ and 2 .

\begin{tabular}{|c|c|c|}
\hline Compound & {$\left[\mathrm{Mg}\left(\mathrm{H}_{2} \mathrm{O}\right)(\mathrm{N}-\mathrm{MeIm})_{2}(4-\mathrm{nba})_{2}\right]_{2} \mathbf{1}$} & {$\left[\mathrm{Mg}\left(\mathrm{H}_{2} \mathrm{O}\right)_{6}\right](4-n b a)_{2} 2 \mathrm{H}_{2} \mathrm{O} 2$} \\
\hline Formula & $\mathrm{C}_{44} \mathrm{H}_{44} \mathrm{Mg}_{2} \mathrm{~N}_{12} \mathrm{O}_{18}$ & $\mathrm{C}_{14} \mathrm{H}_{24} \mathrm{MgN}_{2} \mathrm{O}_{16}$ \\
\hline Temperature $[\mathrm{K}]$ & $293(2)$ & $293(2)$ \\
\hline Wavelength [pm] & 71.073 & 71.073 \\
\hline Space group & Triclinic, $P \overline{\mathbf{1}}$ & Triclinic, $P \overline{\mathbf{1}}$ \\
\hline$a[\AA]$ & $8 \cdot 3235(6)$ & $6 \cdot 0182(14)$ \\
\hline$b[\AA]$ & $11 \cdot 1564(8)$ & $7 \cdot 4098(18)$ \\
\hline$c[\AA]$ & $13 \cdot 9034(11)$ & $12 \cdot 3517(17)$ \\
\hline$\alpha\left[^{\circ}\right]$ & $92 \cdot 89(1)$ & $98 \cdot 58(2)$ \\
\hline$\beta\left[^{\circ}\right]$ & $97 \cdot 06(1)$ & $96 \cdot 81(2)$ \\
\hline$\gamma\left[^{\circ}\right]$ & $90 \cdot 08(1)$ & $91 \cdot 74(2)$ \\
\hline Volume $\left[\AA^{3}\right]$ & $1279 \cdot 6(2)$ & $540 \cdot 2(2)$ \\
\hline$Z$ & 1 & 1 \\
\hline$\mu\left[\mathrm{mm}^{-1}\right]$ & $0 \cdot 132$ & $0 \cdot 17$ \\
\hline$F(000)$ & 560 & 262 \\
\hline Crystal size $\left[\mathrm{mm}^{3}\right]$ & $0.5 \times 0.4 \times 0.4$ & $0.2 \times 0.1 \times 0.1$ \\
\hline Molecular weight $[\mathrm{g} / \mathrm{mol}]$ & 1077.53 & $500 \cdot 66$ \\
\hline Density (calcd.) $\left[\mathrm{g} \mathrm{cm}^{-3}\right]$ & $1 \cdot 398$ & 1.539 \\
\hline$h k l$ Range & $-10 / 10,-14 / 14,-18 / 18$ & $0 / 8,-10 / 10,-17 / 17$ \\
\hline $2 \theta$ range $\left({ }^{\circ}\right)$ & $4 \cdot 82-56 \cdot 10$ & $3-60$ \\
\hline Reflections collected & 14594 & 3456 \\
\hline Reflections unique & 5953 & 3176 \\
\hline Data $\left(F_{O}>2 \sigma\left(F_{O}\right)\right)$ & 4629 & 2242 \\
\hline$R_{\text {int }}$ & 0.0308 & $0 \cdot 0220$ \\
\hline$\Delta \rho\left[\mathrm{e} / \AA^{3}\right]$ & $0.326 /-0.232$ & $0 \cdot 41 /-0 \cdot 36$ \\
\hline Parameters & 346 & 152 \\
\hline$R 1\left[F_{O}>2 \sigma\left(F_{O}\right)\right]$ & $0 \cdot 0449$ & $0 \cdot 0465$ \\
\hline$W R 2$ for all unique data & $0 \cdot 1219$ & $0 \cdot 1432$ \\
\hline Goodness of fit & 1.034 & 1.025 \\
\hline
\end{tabular}

By this disordering alternative hydrogen bonding interactions occur. The $\mathrm{H}$ atoms of all the coordinated water molecules of $\mathbf{1}$ and $\mathbf{2}$ were located in the difference Fourier maps and refined with fixed isotropic displacement parameters. The technical details of data acquisition and some selected refinement results for both the compounds are summarized in table 1 .

\section{Results and discussion}

\subsection{Synthesis}

For the synthesis of $\mathrm{Mg}$ (II)-carboxylates, two synthetic methods, which differ in terms of the metal source can be used. The syntheses involve either the aqueous reaction of $\mathrm{MgCO}_{3}$ with 4-nbaH in a $1: 2$ mole ratio or the reaction of $\mathrm{MgCl}_{2}$ with 4-nbaH in the presence of a weak base like $\mathrm{NaHCO}_{3}$. Although the metal carbonate route takes a longer reaction time as well as higher temperature $\left(100^{\circ} \mathrm{C}\right)$ in order to solubilize the insoluble carbonate in the presence of the aromatic acid, which is also insoluble, the method is slightly advantageous, in that the carbonate anion is removed in the form of $\mathrm{CO}_{2}$. In the chloride route performed at room temperature, the chloride anions remain in solution as the highly soluble $\mathrm{NaCl}$ and the less soluble carboxylate crystallizes out. It is to be noted that the synthesis of the hexaaquomagnesium(II) bis(4-nitrobenzoate) dihydrate 2 by the carbonate route has been described by us in an earlier report along with its spectral and thermal characteristics. ${ }^{22}$ But the crystal structure was not reported. In the present work we have investigated the reactions of $\mathrm{Mg}$ (II) with 4-nbaH in the presence of excess N-MeIm and this reaction results in the formation of a new complex containing $\mathrm{Mg}: 4-\mathrm{nbaH}: \mathrm{N}-\mathrm{MeIm}$ in a $1: 2: 2$ mole ratio as evidenced by the analytical data. In the absence of the $\mathrm{N}$-donor ligand the previously reported complex $\mathbf{2}$ was isolated indicating that $\mathbf{2}$ is a probable intermediate in the formation of 1 . Compound 1 is not stable in acid as evidenced by its decomposition in dilute $\mathrm{HCl}$ resulting in the quantitative formation of 
insoluble 4-nbaH, which was analyzed as described earlier. $^{22}$

\subsection{Spectral and thermal studies}

The electronic spectrum of $\mathbf{1}$ exhibits a signal at around $274 \mathrm{~nm}$ and is similar to that of the N-MeIm free complex 2. This signal can be assigned to the intramolecular charge transfer transition of the aromatic acid. The infrared spectrum of 1 exhibits several sharp bands in the mid IR region, indicating the presence of the organic moieties. A comparison of the IR spectrum of 1 with that of $\mathbf{2}$ reveals the presence of additional bands in $\mathbf{1}$ as well as a different profile in the region above $3000 \mathrm{~cm}^{-1}$ (see web version). The additional bands in $\mathbf{1}$ can be attributed to, as originating from the N-MeIm ligand. Further the differing nature of spectra in the carboxylate region (1650 to $1400 \mathrm{~cm}^{-1}$ ) can probably be due to a differing ligational mode of the 4-nba ligand in the mixed ligand compound. However, no definite conclusions can be drawn on the structure based on IR data alone. The X-ray powder pattern of 1 shows several sharp reflections indicating its crystalline nature and the pattern is quite different from 2 (see web version). The differing nature of the pale yellow complex $\mathbf{1}$ is also further evidenced from the isothermal mass loss studies. Complex 1 is thermally more stable as compared to $\mathbf{2}$ and does not exhibit any loss in weight when heated on a water bath unlike 2, which starts decomposing at $60^{\circ} \mathrm{C}$. When heated at a slightly higher temperature of $130^{\circ} \mathrm{C}$ the observed mass loss of $7.3 \%$ is more than twice the expected value (3.35\%) for emission of only water. All efforts to prepare the anhydrous compound were not successful. Pyrolysis of 1 in a Bunsen flame or alternatively in a furnace at $800^{\circ} \mathrm{C}$ resulted in the formation of a white residue, which was identified as the binary metal oxide based on the mass loss as well as metal analysis. The complete loss of organic part could also be evidenced from the featureless IR spectrum. The TG-DTA study of 1 (figure 1) further reinforces these observations. Thus the TG-DTA thermogram exhibits an endothermic event with a DTA peak at $132^{\circ} \mathrm{C}$, which can be attributed to the emission of coordinated water. However the observed mass loss of $4.66 \%$ is slightly more than the expected value of $3.35 \%$ indicating that the removal of water results in further mass loss which is also evidenced by the rapid drop in the TG curve. The TG curve exhibits a second endothermic event at $218^{\circ} \mathrm{C}$, which can be attributed to the possible removal of the neutral NMeIm ligand. The remaining events at 348, 412, 528 and $554^{\circ} \mathrm{C}$ are exothermic indicating the decomposition of the complex, resulting in the formation of a white residue. In the absence of associated mass spectral data of the emitted fragments, no definite conclusions can be drawn on the nature of decomposition process. Above $600^{\circ} \mathrm{C}$ the TG curve is parallel to the $\mathrm{X}$-axis and the observed residue of $7.4 \%$ is in good agreement with the expected value of $7.4 \%$ for the formation of $\mathrm{MgO}$. The formation of the oxide phase is further confirmed by its X-ray powder pattern. Taken together, the colour as well as the observed yield in the synthesis, analytical data, IR spectra, powder pattern, TG-DTA and weight loss studies, reveal the formation of a new complex containing $\mathrm{Mg}(\mathrm{II}), 4-\mathrm{nba}$ and the $\mathrm{N}$-donor ligand in a $1: 2: 2$ stoichiometry. The results of the crystal structure determination described below, add more credence to the above observations.

\subsection{Description of crystal structures}

Complex 1 crystallizes in the centrosymmetric triclinic space group $\mathrm{P} \overline{1}$ and its asymmetric unit consists of half of the dimeric complex molecule. In the centrosymmetric dimer, each $\mathrm{Mg}$ atom is coordinated to an aquo ligand, two monodentate N-MeIm ligands and a monodentate 4-nba ligand. The second 4-nitrobenzoate ligand functions as a bridging bidentate ligand, linking the metal centers and completes the hexacoordination around each $\mathrm{Mg}$ (II) (figure 2). This binding mode of the 4-nba ligand re-

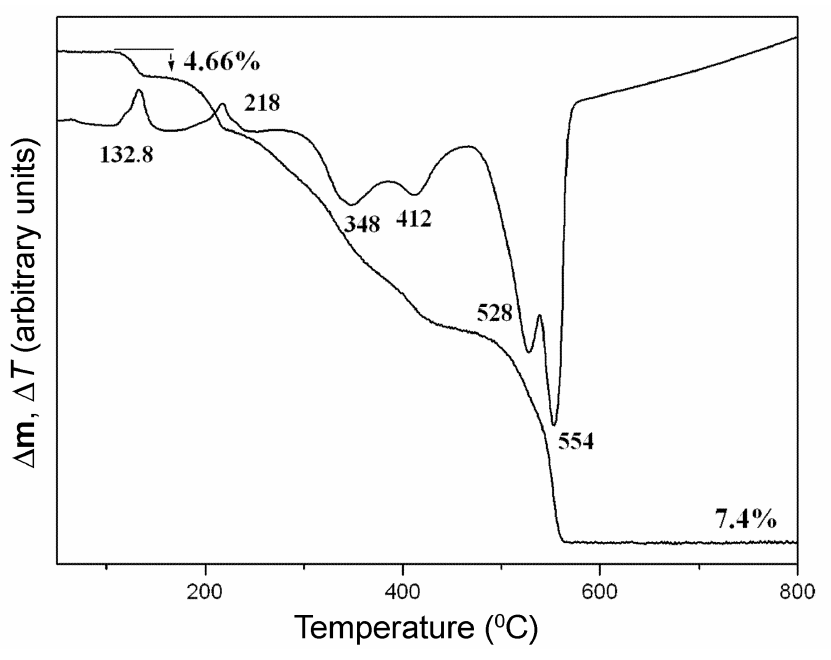

Figure 1. TG-DTA thermogram of complex $\mathbf{1}$. 


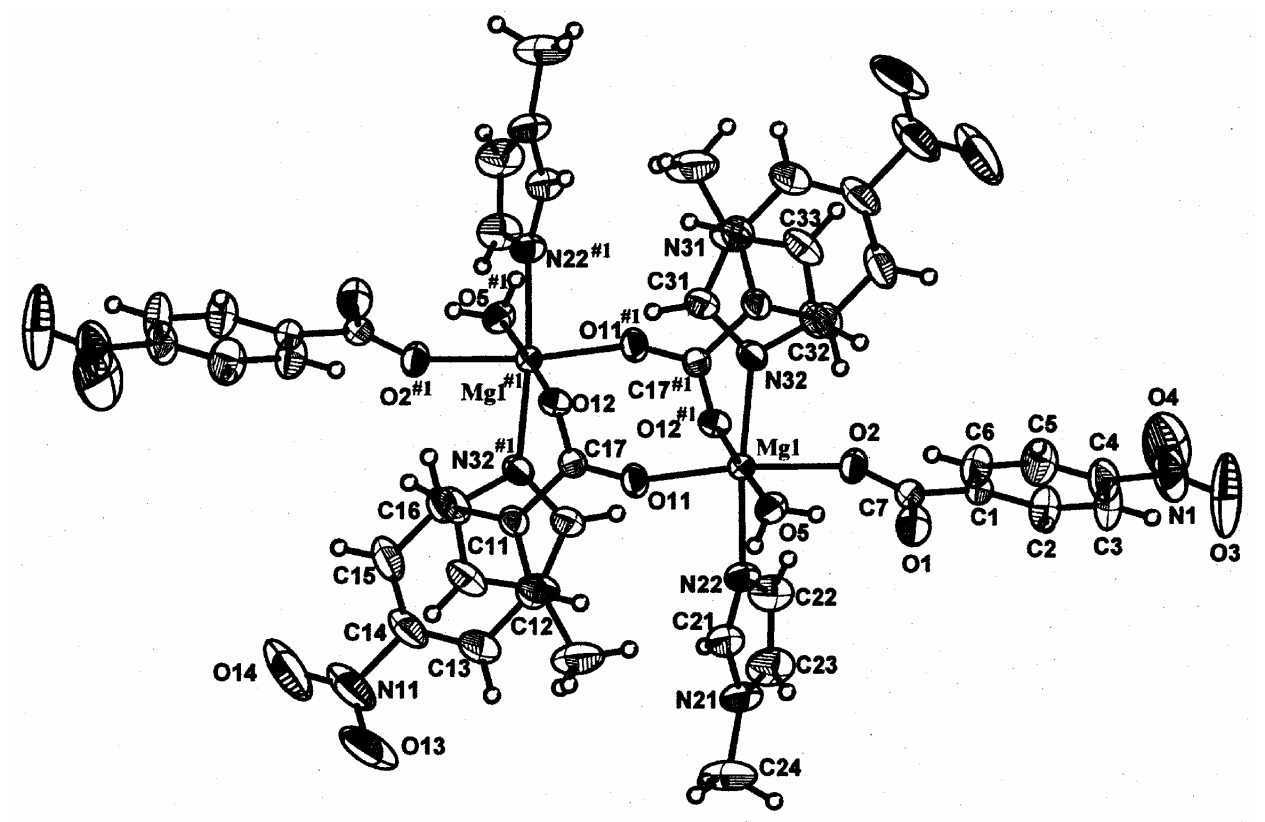

Figure 2. The crystal structure of 1 showing the atom-labelling scheme. Displacement ellipsoids are drawn at the $50 \%$ probability level except for the hydrogen atoms, which are shown as circles of arbitrary radius. Symmetry code: $\# 1-x,-y+2,-z+1$.

Table 2. Selected Bond lengths and angles $\left[\AA{ }^{\circ}\right]$ for $\left[\mathrm{Mg}\left(\mathrm{H}_{2} \mathrm{O}\right)(\mathrm{N}-\mathrm{MeIm})_{2}(4-\mathrm{nba})_{2}\right]_{2} \mathbf{1}$.

\begin{tabular}{llll}
\hline $\mathrm{Mg}(1)-\mathrm{O}(11)$ & $2 \cdot 0395(11)$ & $\mathrm{Mg}(1)-\mathrm{O}(5)$ & $2 \cdot 1170(11)$ \\
$\mathrm{Mg}(1)-\mathrm{O}(12) \# 1$ & $2 \cdot 0715(11)$ & $\mathrm{Mg}(1)-\mathrm{N}(32)$ & $2 \cdot 1780(13)$ \\
$\mathrm{Mg}(1)-\mathrm{O}(2)$ & $2 \cdot 1105(11)$ & $\mathrm{Mg}(1)-\mathrm{N}(22)$ & $2 \cdot 1986(13)$ \\
& & & \\
$\mathrm{O}(11)-\mathrm{Mg}(1)-\mathrm{O}(12) \# 1$ & $94 \cdot 68(4)$ & $\mathrm{O}(2)-\mathrm{Mg}(1)-\mathrm{N}(32)$ & $89 \cdot 39(5)$ \\
$\mathrm{O}(11)-\mathrm{Mg}(1)-\mathrm{O}(2)$ & $171 \cdot 57(4)$ & $\mathrm{O}(5)-\mathrm{Mg}(1)-\mathrm{N}(32)$ & $89 \cdot 18(5)$ \\
$\mathrm{O}(12) \# 1-\mathrm{Mg}(1)-\mathrm{O}(2)$ & $92 \cdot 47(4)$ & $\mathrm{O}(11)-\mathrm{Mg}(1)-\mathrm{N}(22)$ & $90 \cdot 75(5)$ \\
$\mathrm{O}(11)-\mathrm{Mg}(1)-\mathrm{O}(5)$ & $86 \cdot 54(4)$ & $\mathrm{O}(12) \# 1-\mathrm{Mg}(1)-\mathrm{N}(22)$ & $89 \cdot 45(5)$ \\
$\mathrm{O}(12) \# 1-\mathrm{Mg}(1)-\mathrm{O}(5)$ & $178 \cdot 13(4)$ & $\mathrm{O}(2)-\mathrm{Mg}(1)-\mathrm{N}(22)$ & $84 \cdot 85(5)$ \\
$\mathrm{O}(2)-\mathrm{Mg}(1)-\mathrm{O}(5)$ & $86 \cdot 43(4)$ & $\mathrm{O}(5)-\mathrm{Mg}(1)-\mathrm{N}(22)$ & $91 \cdot 97(5)$ \\
$\mathrm{O}(11)-\mathrm{Mg}(1)-\mathrm{N}(32)$ & $95 \cdot 16(5)$ & $\mathrm{N}(32)-\mathrm{Mg}(1)-\mathrm{N}(22)$ & $174 \cdot 04(5)$ \\
$\mathrm{O}(12) \# 1-\mathrm{Mg}(1)-\mathrm{N}(32)$ & $89 \cdot 29(5)$ & & \\
\hline
\end{tabular}

Symmetry transformations used to generate equivalent atoms: \#1 $-x,-y+2,-z+1$

sults in the formation of the characteristic eight membered ring observed in bridged dinuclear carboxylates, consisting of two $\mathrm{Mg}$ atoms, four oxygen atoms and two carbon atoms from the carboxylate moieties of the bridging ligands. The observed bond lengths and bond angles of the organic moieties are in the normal range. The $\mathrm{Mg} 1-\mathrm{O} 2$ bond distance observed for the monodentate 4-nba in $\mathbf{1}$ is shorter at $2 \cdot 1105(11) \AA$ as compared to the $\mathrm{Mg}-\mathrm{O}$ bond distances of the bridging bidentate 4-nba ligand (table 2). The $\mathrm{Mg}-\mathrm{N}$ bond lengths in $\mathbf{1}$ are slightly longer than the reported ${ }^{25} \mathrm{Mg}-\mathrm{N}$ bond length of $2 \cdot 1726(17) \AA$ in the mononuclear Mg-imidazole complex $\left[\mathrm{Mg}\left(\mathrm{H}_{2} \mathrm{O}\right)_{2}(\mathrm{Im})_{2}(4-\mathrm{nba})_{2}\right]$. The cis $\mathrm{O}-\mathrm{Mg}-$ $\mathrm{O}$ and $\mathrm{O}-\mathrm{Mg}-\mathrm{N}$ angles in 1 range from 84.85(5) to $95 \cdot 16(5)^{\circ}$ with one of the angles close to the ideal value, while the trans bond angles range from $171.51(4)$ to $178 \cdot 13(4)^{\circ}$ indicating a slight distortion of the $\left\{\mathrm{MgO}_{4} \mathrm{~N}_{2}\right\}$ octahedron. An analysis of the structure reveals that the dimeric $\mathrm{Mg}$ (II) complex 1 exhibits two short H-bonding interactions accompanied by large DHA angles (table 3 ) between a coordinated water and the free oxygen atom of the monodentate 4-nba. Both these $\mathrm{O}-\mathrm{H} \cdots \mathrm{O}$ contacts are much shorter than the sum of their van der Waals radii $^{28}$ and the coordinated water functions as a 


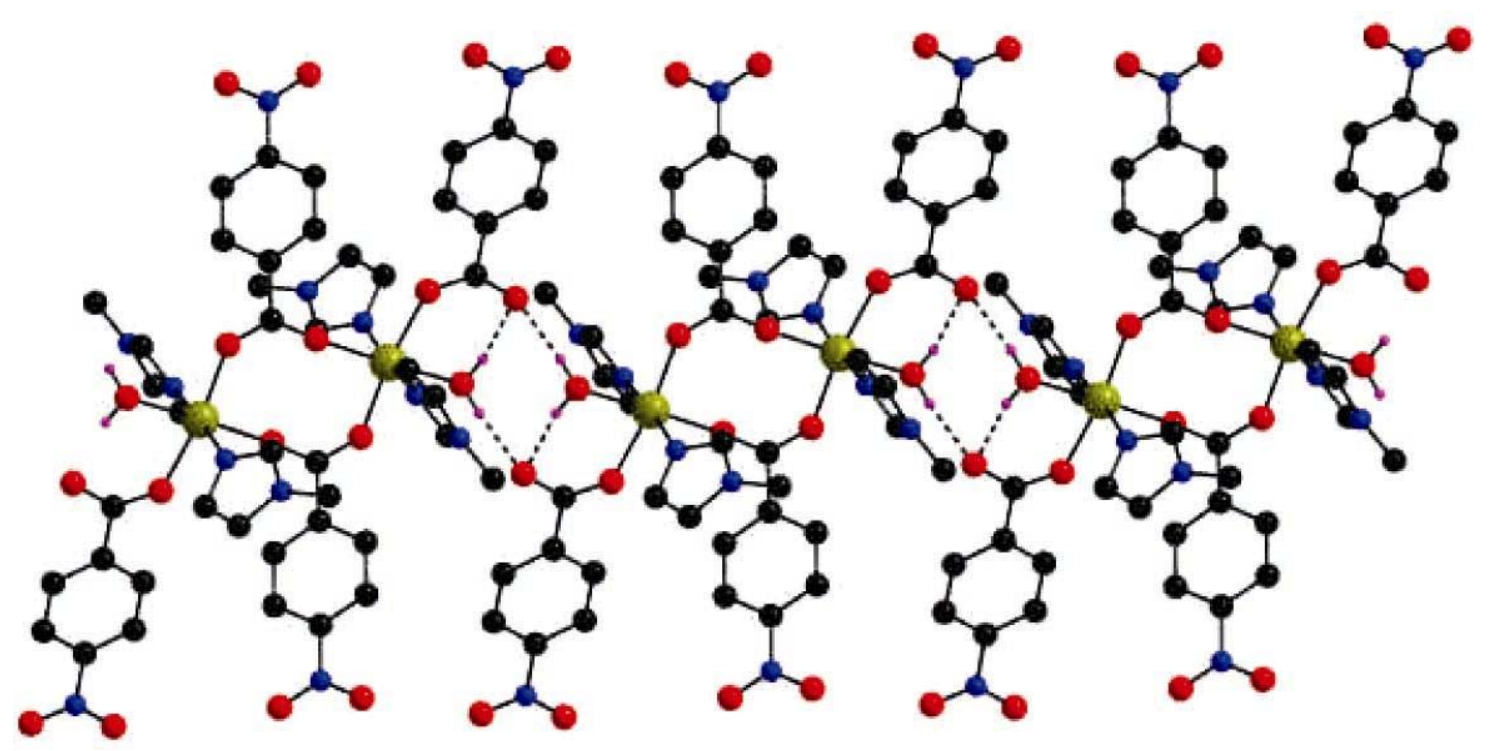

Figure 3. Linking of a dimeric complex 1 with the next unit along $b$ by an intermolecular H-bond resulting in the formation of a one-dimensional network. For clarity the $\mathrm{H}$ atoms attached to $\mathrm{C}$ are not shown.

Table 3. Hydrogen-bonding geometry $\left(\AA,{ }^{\circ}\right)$ for $[\mathrm{Mg}$ $\left.\left(\mathrm{H}_{2} \mathrm{O}\right)(\mathrm{N}-\mathrm{MeIm})_{2}(4-\mathrm{nba})_{2}\right]_{2} \mathbf{1}$.

\begin{tabular}{|c|c|c|c|c|}
\hline $\mathrm{D}-\mathrm{H} \cdots \mathrm{A}$ & $(\mathrm{D}-\mathrm{H})$ & $(\mathrm{H} \cdots \mathrm{A})$ & $(\mathrm{D} \cdots \mathrm{A})$ & $<\mathrm{DHA}$ \\
\hline $\mathrm{O} 5-\mathrm{H} 1 \mathrm{O} 5 \cdots \mathrm{O}^{\mathrm{i}}$ & 0.84 & $1 \cdot 987$ & $2 \cdot 809$ & 166 \\
\hline $\mathrm{O} 5-\mathrm{H} 2 \mathrm{O} 5 \cdots \mathrm{O} 1$ & 0.84 & 1.922 & $2 \cdot 738$ & 163 \\
\hline
\end{tabular}

Symmetry code: i) $-x,-y+1,-z+1$
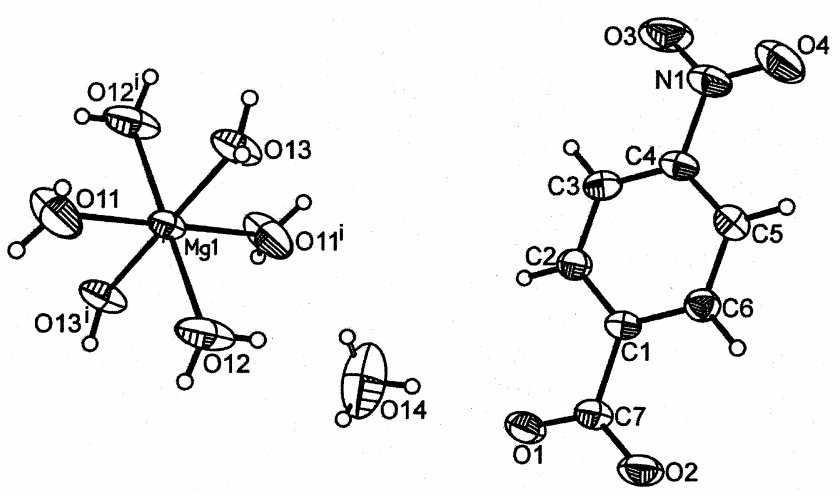

Figure 4. The crystal structure of 2 showing the atomlabelling scheme. Displacement ellipsoids are drawn at the $50 \%$ probability level except for the hydrogen atoms, which are shown as circles of arbitrary radius. One of the $\mathrm{H}$ atoms attached to the lattice water $(\mathrm{O} 14)$ is disordered over two positions. Symmetry code: $\# \mathrm{i}-x,-y,-z+1$.

singly shared H-donor and the free carboxylate oxygen $\mathrm{O} 1$ functions as a $\mathrm{H}$-acceptor. One of these $\mathrm{H}$-bonds, is intramolecular and the other intermolecular, link- ing a dimeric unit with the next resulting in the formation of a one-dimensional H-bonded network along $b$ (figure 3 ).

Compound 2 crystallizes in the centrosymmetric triclinic space group $\mathrm{P}_{\overline{1}}$ and the $\mathrm{Mg}(\mathrm{II})$ is located on an inversion centre. The structure of 2 consists of a $\left[\mathrm{Mg}\left(\mathrm{H}_{2} \mathrm{O}\right)_{6}\right]^{2+}$ cation, a free 4-nba anion and a lattice water molecule (figure 4). The octahedral hexaaquomagnesium(II) cation is a well known unit and has been reported in several $\mathrm{Mg}$ (II) complexes. ${ }^{9,10,29}$ The cis $\mathrm{O}-\mathrm{Mg}-\mathrm{O}$ angles in the $\left\{\mathrm{MgO}_{6}\right\}$ octahedron range from $88.6^{\circ}$ to $91.5^{\circ}$ (table 4 ). The $\mathrm{Mg}-\mathrm{O}$ bond distances in the $\left[\mathrm{Mg}\left(\mathrm{H}_{2} \mathrm{O}\right)_{6}\right]^{2+}$ unit of 2 range from 2.046(2) to 2.088(2) $\AA$ and are shorter than the observed $\mathrm{Mg}-\mathrm{O}\left(\mathrm{H}_{2} \mathrm{O}\right)$ bond distance of $2 \cdot 1170(11)$ in the dinuclear complex 1 . The observed bond lengths and bond angles of the 4-nba anion are in the normal range and are comparable with those reported for compounds containing the free 4-nba anion. ${ }^{30}$ An analysis of the crystal structure reveals that the monomeric $\mathrm{Mg}(\mathrm{II})$ complex 2 exhibits several $\mathrm{H}$ bonding interactions through all possible sites, with the oxygen atoms of the carboxylate and nitro groups functioning as $\mathrm{H}$-acceptors, while the $\mathrm{H}$ atoms of the coordinated waters act as H-donors. The lattice water $(\mathrm{O} 14)$ functions as $\mathrm{H}$-donor and is linked intramolecularly to the carboxylate oxygen $\mathrm{Ol}$ via

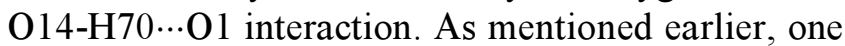
of the $\mathrm{H}$ atoms attached to the lattice water is disordered over two positions (H80 and H90). The disordered 
Table 4. Selected bond lengths and angles $\left[\AA,{ }^{\circ}\right]$ for $\left[\mathrm{Mg}\left(\mathrm{H}_{2} \mathrm{O}\right)_{6}\right](4-\mathrm{nba})_{2} \cdot 2 \mathrm{H}_{2} \mathrm{O} 2$.

\begin{tabular}{llll}
\hline $\mathrm{Mg}(1)-\mathrm{O}(11)$ & $2 \cdot 088(2)$ & $\mathrm{Mg}(1)-\mathrm{O}(11) \# 1$ & $2 \cdot 088(2)$ \\
$\mathrm{Mg}(1)-\mathrm{O}(12)$ & $2 \cdot 066(2)$ & $\mathrm{Mg}(1)-\mathrm{O}(12) \# 1$ & $2 \cdot 066(2)$ \\
$\mathrm{Mg}(1)-\mathrm{O}(13)$ & $2 \cdot 046(2)$ & $\mathrm{Mg}(1)-\mathrm{O}(13) \# 1$ & $2 \cdot 046(2))$ \\
& & & \\
$\mathrm{O}(13)-\mathrm{Mg}(1)-\mathrm{O}(12) \# 1$ & $88 \cdot 6(1)$ & $\mathrm{O}(13) \# 1-\mathrm{Mg}(1)-\mathrm{O}(12) \# 1$ & $91 \cdot 5(1)$ \\
$\mathrm{O}(13)-\mathrm{Mg}(1)-\mathrm{O}(12)$ & $91 \cdot 5(1)$ & $\mathrm{O}(13) \# 1-\mathrm{Mg}(1)-\mathrm{O}(12)$ & $88 \cdot 6(1)$ \\
$\mathrm{O}(13)-\mathrm{Mg}(1)-\mathrm{O}(11)$ & $89 \cdot 9(1)$ & $\mathrm{O}(13) \# 1-\mathrm{Mg}(1)-\mathrm{O}(11)$ & $90 \cdot 1(1)$ \\
$\mathrm{O}(12) \# 1-\mathrm{Mg}(1)-\mathrm{O}(11)$ & $89 \cdot 6(1)$ & $\mathrm{O}(12)-\mathrm{Mg}(1)-\mathrm{O}(11)$ & $90 \cdot 4(1)$ \\
$\mathrm{O}(13)-\mathrm{Mg}(1)-\mathrm{O}(11) \# 1$ & $90 \cdot 1(1)$ & $\mathrm{O}(13) \# 1-\mathrm{Mg}(1)-\mathrm{O}(11) \# 1$ & $89 \cdot 9(1)$ \\
$\mathrm{O}(12) \# 1-\mathrm{Mg}(1)-\mathrm{O}(11) \# 1$ & $90 \cdot 4(1)$ & $\mathrm{O}(12)-\mathrm{Mg}(1)-\mathrm{O}(11) \# 1$ & $89 \cdot 6(1)$ \\
$\mathrm{O}(11)-\mathrm{Mg}(1)-\mathrm{O}(11) \# 1$ & $180 \cdot 0(1)$ & $\mathrm{O}(13)-\mathrm{Mg}(1)-\mathrm{O}(13) \# 1$ & $180 \cdot 0$ \\
$\mathrm{O}(12) \# 1-\mathrm{Mg}(1)-\mathrm{O}(12)$ & $180 \cdot 0$ & & \\
\hline
\end{tabular}

Symmetry transformations used to generate equivalent atoms: $\# 1-x,-y,-z+1$

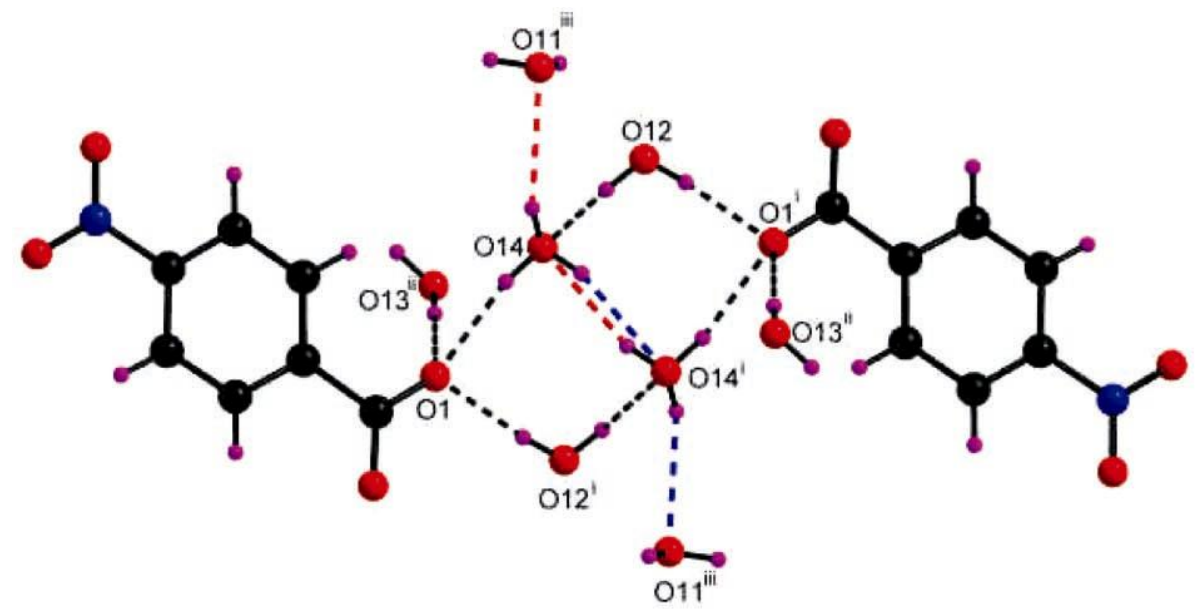

Figure 5. A view of the surroundings of the lattice water showing the $\mathrm{H}$-acceptor bonds with the coordinated waters $\mathrm{O} 11$ and $\mathrm{O} 12$, a $\mathrm{H}$-donor bond $(\mathrm{O} 14-\mathrm{H} 7 \mathrm{O} \cdots \mathrm{O} 1)$ to the carboxylate oxygen $\mathrm{O} 1$. The $\mathrm{H}$ atom involved in the formation of the centrosymmetric cyclic water dimer is disordered over two positions. The red and blue dotted lines indicate the H-bonding of the disordered atoms. Symmetry codes: i) $-x+1$, $-y+1,-z+1$; ii) $x y-1, z$; iii) $-x,-y,-z+1$.

hydrogen (H80) on $\mathrm{Ol} 4$ is $\mathrm{H}-$ bonded to another lattice water through $\mathrm{O} 14-\mathrm{H} 80 \cdots \mathrm{O} 14$ bond, while the $\mathrm{H} 90$ is linked to a coordinated water $\mathrm{O} 11$ via $\mathrm{O} 14$ $\mathrm{H} 9 \mathrm{O} \cdots \mathrm{O} 11$ bond resulting in the formation of a centrosymmetric cyclic water cluster (figure 5). The

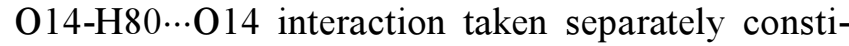
tutes a centrosymmetric cyclic water dimer.

Water oligomers have been extensively investigated by spectroscopic methods ${ }^{31,32}$ and theoretical calculations. ${ }^{33-35}$ In recent years the crystallographic identification of several H-bonded water clusters ${ }^{36}$ especially linear water dimers in crystalline hydrates has been reported. ${ }^{37-39}$ The patterns of water clusters within the Cambridge Structural Database (CSD Version 5.23 April 2002) have been reviewed by In- fantes and Motherwell ${ }^{21}$ and classified as discrete chains and rings, infinite chains and tapes, and layer structures. According to this classification many of the reported water clusters fall in the category of discrete chains with water dimers accounting for the majority of the structures. Interestingly there is no mention of a cyclic water dimer in this review. ${ }^{21}$ In a recent paper, Das and coworkers have reported on the identification of a water nonamer, which features an inbuilt cyclic water dimer, in a tetranuclear copper complex. ${ }^{40}$ To the best of our knowledge, there is no other cyclic water dimer crystallographically characterized till date, other than the inbuilt cyclic water dimer mentioned above. The observed $\mathrm{O} \cdots \mathrm{H}$ and $\mathrm{O} \cdots \mathrm{O}$ distances of 2.282 and $3.031 \AA$ in the cyclic 


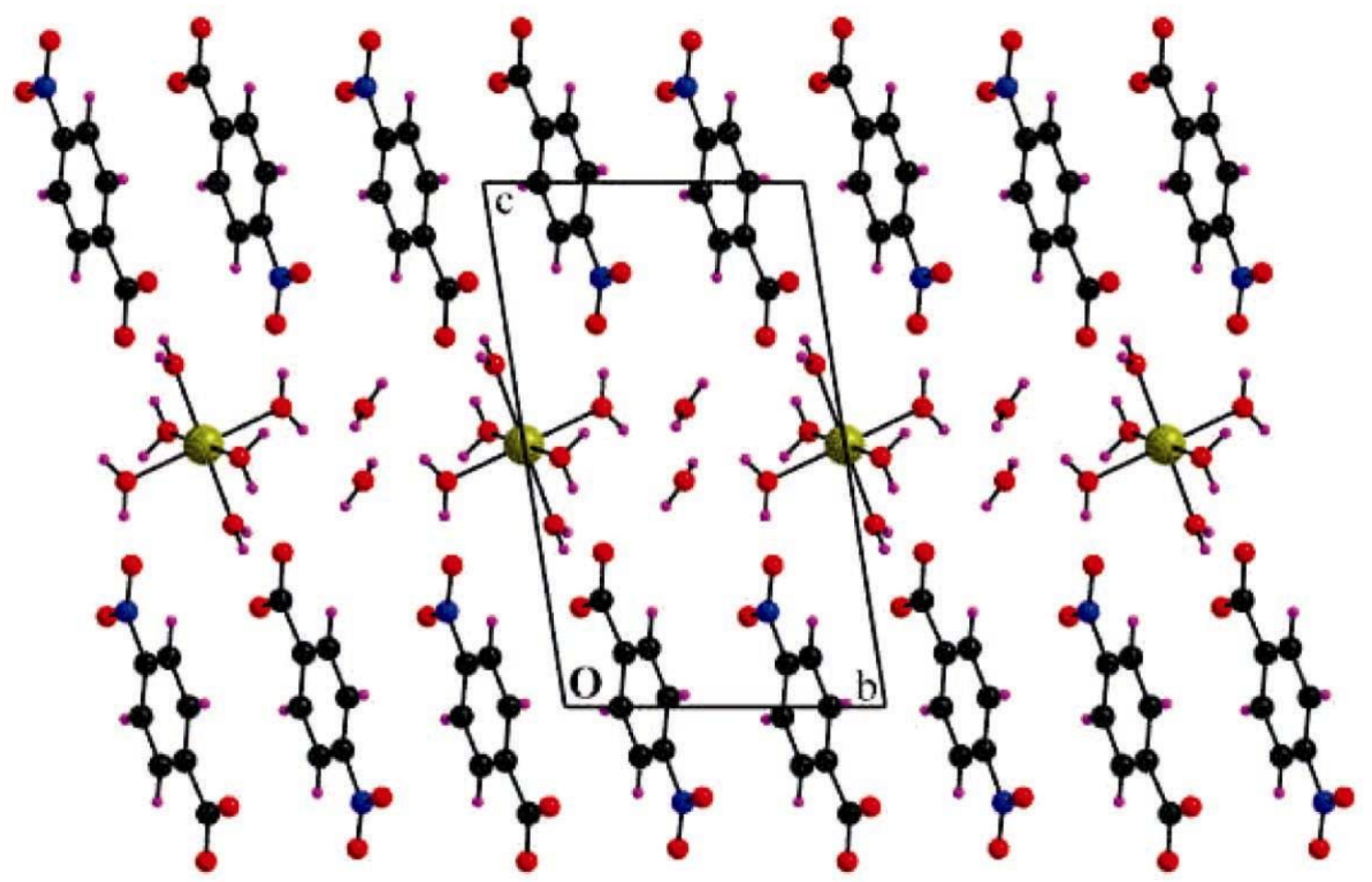

Figure 6. A view of the packing of 2 showing the alternating layers of $\left[\mathrm{Mg}\left(\mathrm{H}_{2} \mathrm{O}\right)_{6}\right]^{2+}$ cations and 4nitrobenzoate anions in the crystallographic $b c$ plane. The lattice waters are located between the cations, while the anions are arranged antiparallel to each other along $b$. For clarity H-bonds are not shown.

Table 5. Hydrogen-bonding geometry $\left(\AA,{ }^{\circ}\right)$ for $\left[\mathrm{Mg}\left(\mathrm{H}_{2} \mathrm{O}\right)_{6}\right](4-\mathrm{nba})_{2} \cdot 2 \mathrm{H}_{2} \mathrm{O} 2$.

\begin{tabular}{|c|c|c|c|c|}
\hline $\mathrm{D}-\mathrm{H} \cdots \mathrm{A}$ & $(\mathrm{D}-\mathrm{H})$ & $(\mathrm{H} \cdots \mathrm{A})$ & $(\mathrm{D} \cdots \mathrm{A})$ & $<\mathrm{DHA}$ \\
\hline $\mathrm{O} 11-\mathrm{H} 1 \mathrm{O} \cdots \mathrm{O} 14^{\mathrm{ii}}$ & $0 \cdot 82$ & 1.988 & $2 \cdot 803$ & 172 \\
\hline $\mathrm{O} 11-\mathrm{H} 2 \mathrm{O} \cdots \mathrm{O} 3^{\text {iv }}$ & $0 \cdot 82$ & $2 \cdot 402$ & $3 \cdot 216$ & 172 \\
\hline $\mathrm{O} 11-\mathrm{H} 2 \mathrm{O} \cdots \mathrm{O} 4^{\mathrm{iv}}$ & $0 \cdot 82$ & $2 \cdot 407$ & $3 \cdot 029$ & 133 \\
\hline $\mathrm{O} 12-\mathrm{H} 3 \mathrm{O} \cdots \mathrm{O}^{1}{ }^{1}$ & $0 \cdot 82$ & $1 \cdot 830$ & $2 \cdot 646$ & 174 \\
\hline $\mathrm{O} 12-\mathrm{H} 4 \mathrm{O} \cdots \mathrm{O} 14$ & $0 \cdot 82$ & $2 \cdot 428$ & $3 \cdot 103$ & 140 \\
\hline $\mathrm{O} 13-\mathrm{H} 5 \mathrm{O} \cdots \mathrm{O} 2^{\mathrm{v}}$ & $0 \cdot 82$ & 1.830 & $2 \cdot 648$ & 176 \\
\hline $\mathrm{O} 13-\mathrm{H} 6 \mathrm{O} \cdots \mathrm{O} 1^{\mathrm{ii}}$ & $0 \cdot 82$ & $2 \cdot 030$ & $2 \cdot 849$ & 177 \\
\hline $\mathrm{O} 14-\mathrm{H} 7 \mathrm{O} \cdots \mathrm{O} 1$ & $0 \cdot 82$ & $1 \cdot 994$ & $2 \cdot 783$ & 161 \\
\hline $\mathrm{O} 14-\mathrm{H} 8 \mathrm{O} \cdots \mathrm{O} 14^{\mathrm{i}}$ & $0 \cdot 82$ & $2 \cdot 233$ & $3 \cdot 031$ & 165 \\
\hline $\mathrm{O} 14-\mathrm{H} 9 \mathrm{O} \cdots \mathrm{O} 11^{\mathrm{iii}}$ & $0 \cdot 82$ & $2 \cdot 315$ & $2 \cdot 977$ & 138 \\
\hline
\end{tabular}

Symmetry code: i) $-x+1,-y+1,-z+1$; ii) $x, y-1, z$; iii) $-x,-y,-z+1$; iv) $x, y-1, z-1$; v) $x-1, y-1, z$

water dimer in $\mathbf{2}$ are shorter than the sum of their van der Waals radii but longer than the reported values for nearly linear water dimers identified in other crystalline environments ${ }^{37-39}$ and the inbuilt cyclic water dimer. ${ }^{40}$ Interestingly the $\mathrm{OHO}$ angle of $165^{\circ}$ which indicates a strong interaction, is more than the reported value of $160^{\circ}$ for the inbuilt cyclic water dimer. ${ }^{40}$ The disorder of the hydrogen atom involved in the formation of the cyclic water dimer can probably account for the observed metric parameters

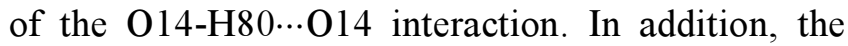
lattice water forms $\mathrm{H}$-acceptor bonds with the coordinated waters intra- as well as intermolecularly resulting in the bridging of the cyclic water dimer by four $\left[\mathrm{Mg}\left(\mathrm{H}_{2} \mathrm{O}\right)_{6}\right]^{2+}$ cations. All $\mathrm{H}$-atoms involved in $\mathrm{H}$-bonding are singly shared donors excepting H20 attached to $\mathrm{O} 11$. Unlike the $\mathrm{O} 14$ atom of the lattice water and the $\mathrm{Ol}$ atom of the carboxylate group, which function as trifurcated acceptors, the oxygen atoms of the nitro group as well as the $\mathrm{O} 2$ of the carboxylate act as singly shared acceptors. The observed $\mathrm{O}-\mathrm{H} \cdots \mathrm{O}$ interactions in $\mathbf{2}$ ranging from 1.830 to $2.428 \AA$ are shorter than the sum of their van der Waals radii $^{28}$ and are accompanied by $\mathrm{OHO}$ bond angles ranging from 133 to $177^{\circ}$ (table 5) These interactions lead to the formation of alternating layers of anions and cations in the crystallographic $b c$ plane and the lattice waters are situated between the dications (figure 6). As a result of the H-bonding pattern in 2, the 4-nba anions are arranged antiparallel to each other along $b$. An analysis of the short ring interactions and distances between the ring centroids $(\mathrm{Cg}-\mathrm{Cg})$ indicates a nearly overlapped ar- 
rangement of 4-nba anions in the crystal structure of 2 and the perpendicular distance of $3.388 \AA$ accompanied by $\mathrm{Cg}-\mathrm{Cg}$ distance of $3.674 \AA$ between the 4nba rings is indicative of $\pi-\pi$ stacking interactions.

\subsection{Comparative chemistry of magnesium 4-nitrobenzoate complexes:}

A comparative study of the structures of $\mathbf{1}$ and $\mathbf{2}$ and the recently reported mixed ligand complex ${ }^{25}$ $\left[\mathrm{Mg}\left(\mathrm{H}_{2} \mathrm{O}\right)_{2}(\mathrm{Im})_{2}(4-\mathrm{nba})_{2}\right]$ reveals certain similarities and many differences. In all the three complexes, which contain $\mathrm{Mg}$ and 4-nba in a $1: 2$ ratio the central metal is hexacoordinated. However, the 4-nba anion exhibits different ligational behaviour. In complex 1 both monodentate and bridging bidentate modes of 4-nba are observed, and in 2 the 4-nba is uncoordinated while in the imidazole complex it is monodentate. In all the three complexes, which crystallize in the centrosymmetric triclinic $\mathrm{P}_{\overline{1}}$ space group the metal ion is differently hydrated. Thus the metal : $\mathrm{H}_{2} \mathrm{O}$ ratio is $1: 1$ in the dimeric $\mathrm{Mg}$ complex 1 and $1: 2$ in the $\mathrm{Mg}-\mathrm{Im}$ complex and in both these complexes the waters are coordinated to $\mathrm{Mg}$. In contrast, the $\mathrm{Mg}: \mathrm{H}_{2} \mathrm{O}$ ratio in 2 is $1: 8$ and 2 contains both coordinated and lattice waters. All the three complexes exhibit intermolecular $\mathrm{H}$-bonding interactions and the resulting $\mathrm{H}$-bonded networks are quite different. The complexes $\mathbf{1}$ and $\mathbf{2}$ are H-bonded with the aid of $\mathrm{O}-\mathrm{H} \cdots \mathrm{O}$ interactions, while in $\left[\mathrm{Mg}\left(\mathrm{H}_{2} \mathrm{O}\right)_{2}(\mathrm{Im})_{2}(4-\mathrm{nba})_{2}\right]$ two types of interactions namely $\mathrm{O}-\mathrm{H} \cdots \mathrm{O}$ and $\mathrm{N}-\mathrm{H} \cdots \mathrm{O}$ bonds are observed. The $\mathrm{N}$-donor ligand free complex $\mathbf{2}$ is involved in intermolecular interactions through all its possible sites resulting in the formation of a three dimensional H-bonding network and encapsulating a cyclic water dimer which is further H-bonded to four different hexaaquomagnesium(II) ions. The incorporation of $\mathrm{Im}$ as well as 4-nba in the coordination sphere of $\mathrm{Mg}$ in $\left[\mathrm{Mg}\left(\mathrm{H}_{2} \mathrm{O}\right)_{2}(\mathrm{Im})_{2}(4-\mathrm{nba})_{2}\right]$ results in an intricate three dimensional network with the aid of two varieties of $\mathrm{H}$-bond. In the Im complex only one of the nitro oxygen is $\mathrm{H}$-bonded unlike in 2 where both the oxygen atoms of the $-\mathrm{NO}_{2}$ functionality are $\mathrm{H}$-bonded to the coordinated waters. The incorporation of N-MeIm as well as 4-nba in the coordination sphere of $\mathrm{Mg}$ (II) in 1 results in the formation of a dimeric complex. As expected, the substitution of $\mathrm{H}$ atom attached to the amino $\mathrm{N}$ in $\mathrm{Im}$ by $-\mathrm{CH}_{3}$ in the N-MeIm ligand not only blocks the H-bonding at this site, which is observed in the $\mathrm{Mg}-\mathrm{Im}$ complex, but results in the formation of a one dimensional Hbonded network.

\section{Conclusions}

The aqueous reaction of $\mathrm{MgCl}_{2}$ with sodium 4-nba and N-MeIm or alternatively the reaction of $\mathrm{MgCO}_{3}$ with 4-nbaH and N-MeIm in a $1: 2: 4$ mole ratio results in the formation of the dimeric $\mathrm{Mg}$ complex 1 in good yields. In the absence of any N-donor ligand complex 2 is obtained. Both the compounds are obtained as phase pure solids as evidenced by a comparison of the powder pattern of the bulk sample with that of the calculated pattern from the single crystal data. 1 is thermally more stable as compared to 2 and at elevated temperatures $\left(\sim 800^{\circ} \mathrm{C}\right)$, is decomposed to $\mathrm{MgO}$. Both complexes, which crystallize in the triclinic $P \overline{1}$ space group exhibit different binding modes of the 4-nba ligand. An interesting aspect of the structure of complex $\mathbf{2}$ is the identification of a cyclic water dimer showing that 2 functions as a molecular container for encapsulating a cyclic water dimer. A comparative study of the structures of three magnesium 4-nitrobenzoate complexes reveals that these complexes exhibit a rich structural chemistry in terms of the binding modes of the 4-nba ligand as well as the intermolecular interactions.

\section{Supplementary material}

Infrared spectra and X-ray powder pattern of compounds 1 and 2 , are available on the web version of this paper. Crystallographic data (excluding structure factors) for the structures reported in this paper have been deposited with the Cambridge Crystallographic Data Centre as supplementary publication no. CCDC 635058 (1), CCDC 635059 (2). Copies of the data can be obtained, free of charge, on application to CCDC, 12 Union Road, Cambridge CB2 1 EZ, UK. (fax: +44-(0)1223-336033 or email: deposit@ccdc.cam.ac.uk).

\section{Acknowledgements}

BRS thanks Dr Samar Das (University of Hyderabad), Mr A R Naik and Mr P Raghavaiah for helpful discussions. The authors thank one of the reviewers for helpful suggestions. This work is supported by the Department of Science and Technology, New Delhi under grant no. SR/S1/IC-41/2003. 


\section{References}

1. Cowan J A (ed.) 1995 Biological chemistry of magnesium (New York: VCD)

2. Black C B, Huang H W and Cowan J A 1994 Coord. Chem. Rev. 135165

3. Siegel H and Siegel A (ed.) 1990 Magnesium and its role in biology, nutrition and physiology Vol 26 (New York: Dekker)

4. Schmidbaur H, Classen H G and Helbig J 1990 Angew. Chem. Int. Ed. Engl. 291090

5. Schmidbaur H, Müller G, Riede J, Manninger G, Helbig J 1986 Angew. Chem. Int. Ed. Engl. 251013

6. Wiesbrock F, Nogai S, Schier A and Schmidbaur H 2002 Helv. Chim. Acta 851151

7. Drake S R, Sanderson K D, Hursthouse M B and Malik K M A 1993 Inorg. Chem. 321041

8. Srinivasan B R, Sawant S C and Dhuri S N 2002 Indian J. Chem. A41 290

9. Wiesbrock F, Schier A and Schmidbaur H 2002 Z. Naturforsch. B57 251

10. Murugavel R, Karambelkar V V and Anantharaman G 2000 Indian J. Chem. A39 843

11. Murugavel R, Karambelkar V V, Anantharaman G and Walawalkar M G 2000 Inorg. Chem. 391381

12. Murugavel R and Banerjee S 2003 Inorg. Chem. Comm. 6810

13. Murugavel R, Anantharaman G, Krishnamurthy D, Sathiyendiran M and Walawalkar M G 2000 Proc. Indian Acad. Sci. (Chem. Sci.) 112273

14. Murugavel R, Baheti K and Anantharaman G 2001 Inorg. Chem. $\mathbf{4 0} 6870$

15. Mehrotra R C and Bohra M 1983 Metal carboxylates (London: Academic Press); Mehrotra R C and Singh A 1997 Prog. Inorg. Chem. 46239

16. Cotton F A, Wilkinson G, Murillo C A and Bochmann M 1999 Advanced inorganic chemistry (John Wiley) 6th edn, p. 487

17. Desiraju G R and Steiner T 1999 The weak hydrogen bond in structural chemistry and biology (Oxford: Oxford University Press)

18. Tiekink E R T and Vittal J J (eds) 2006 Frontiers in crystal engineering (England: John Wiley)

19. Mascal M, Infantes L and Chisolm J 2006 Angew. Chem. Int. Ed. Engl. $\mathbf{4 5} 32$
20. Ludwig R 2001 Angew. Chem. Int. Ed. Engl. 40 1808

21. Infantes L and Motherwell S 2002 Cryst. Eng. Commun. 4 454; Infantes L, Chisolm J and Motherwell S 2003 Cryst. Eng. Commun. 5480

22. Srinivasan B R and Sawant S C 2003 Thermochim. Acta 40245

23. Srinivasan B R Sawant S C and Das S K 2004 Indian J. Chem. A43 1066

24. Srinivasan B R, Sawant J V and Raghavaiah P 2006 Indian J. Chem. A45 2392

25. Srinivasan B R, Sawant J V and Raghavaiah P $2007 \mathrm{~J}$ Chem. Sci. 11911

26. Bassett J, Denney R C, Jeffery G H and Mendham J 1978 Vogel's textbook of quantitative inorganic analysis, 4th edn (London: ELBS)

27. Sheldrick G M, 1997 SHELXS-97 and SHELXL-97: Programs for crystal structure solution and refinement, University of Göttingen, Germany

28. Bondi A 1964 J. Phys. Chem. 68441

29. Cole L B and Holt E M 1985 Inorg Chim. Acta 108 159; Dale S H, Elsegood M R J and Kainth S 2003 Acta Crystallogr. C59 m505

30. Hashizume D, Iegaki M, Yasui M, Iwasaki F, Meng J, Wen Z and Matsuura T 2001 Acta Crystallogr. C57 1067

31. Magnusson L B 1970 J. Phys. Chem. 744221

32. Keutsch F N and Saykally R J 2001 Proc. Natl. Acad. Sci. USA 9810533

33. Liu K, Cruzan J D and Saykally R J 1996 Science 271929

34. Kim J, Suh S B, and Kim K S 1999 J. Chem. Phys. 11110077

35. Maheswari S, Patel N, Sathyamurthy N, Kulkarni A D and Gadre S R 2001 J. Phys. Chem. 10510525

36. Supriya S, and Das S K 2003 J. Cluster Sci. 14337

37. Chand D K and Bharadwaj P K 1998 Inorg. Chem. 37 5050; Ghosh S K and Bharadwaj P K 2003 Inorg. Chem. 428250

38. Manikumari S, Shivaiah V and Das S K 2002 Inorg. Chem. 416953

39. Srinivasan B R, Mhalsikar R, Rane K S, Näther C and Bensch W 2007. J. Chem. Sci. 11921

40. Pradeep C P, Supriya S, Zacharias P S and Das S K 2006 Polyhedron 253588 